Boise State University

ScholarWorks

Psychological Sciences Faculty Publications and

Presentations

Department of Psychological Science

$11-11-2008$

\title{
Comparing Sexual-Minority and Heterosexual Young Women's Friends and Parents as Sources of Support for Sexual Issues
}

Elizabeth M. Morgan

Boise State University

Carly K. Friedman

Samford University 


\title{
Comparing Sexual-Minority and Heterosexual Young Women's Friends and Parents as Sources of Support for Sexual Issues
}

\author{
Carly K. Friedman \\ Psychology Department, Samford University, Birmingham, AL \\ Elizabeth M. Morgan \\ Psychology Department, Boise State University, Boise, ID
}

\begin{abstract}
The present study provides a comparative analysis of sexual-minority and heterosexual emerging adult women's experiences seeking support for sexual issues from parents and friends. Participants included 229 college women (88 sexual-minority women; 141 heterosexual women), ranging in age from 18 to 25 years of age, who provided written responses to an inquiry about a time they went to friends and parents for support for a issue related to their sexuality. Responses indicated that the majority of participants had sought support from either a parent or a friend and that mothers and female friends were more likely involved that fathers or male friends, respectively. Sexual issues that participants reported discussing with parents and friends were inductively grouped into five categories: dating and romantic relationships, sexual behavior, sexual health, identity negotiation, and discrimination and violence. Issues that were discussed differed based on sexual orientation identity and the source of support (parent or friend); they did not differ by age. Participants generally perceived parents and friends responses as helpful, though sexualminority participants perceived both parents and friends responses as less helpful than heterosexual participants. Overall, results suggest both similarities and differences between sexual-minority and heterosexual young women's experiences seeking support for sexual issues from parents and friends.
\end{abstract}

Keywords: Social support, Sexual development, Sexual identity, Sexual communication, Sexual problems

Late adolescence and emerging adulthood is a period of significant identity development and often includes increased autonomy and exploration in a number of realms, including sexuality (Arnett, 2004; Lefkowitz, 2005). For many sexual-minority individuals, emerging adulthood is a particularly important time of sexual identity exploration and development (Savin-Williams, 2005). In particular, college often allows young adults to explore samesex and other alternative sexual identities in a more accepting environment (Henderson, 1984; Lefkowitz $\&$ Gillen, 2006). The college context also allows for increased opportunities to engage in same-sex dating and sexual relationships (Evans \& D'Augelli, 2001). Thus, both heterosexual and sexual-minority youth may encounter difficult sexual or relational situations for which they might seek social support. Social support serves as an important context for identity development, including supplying reassurance, providing information to overcome challenges to sexual development, and encouraging identity

Address Correspondence to: Carly K. Friedman, PhD, Department of Psychology, Samford University, Birmingham, AL 35229, PH: 831-345-6302 / FAX: 205-726-2895, E-MAIL: cfriedma@samford.edu exploration. Because relationships with parents and friends are increasingly central in the lives of young adults, it is understandable that youth may seek support for sexual issues within the context of these relationships (Brown, 1999; Connolly \& Goldberg, 1999; Sprecher \& Felmlee, 1992). Sexual issues include a variety of difficulties youth may encounter in their romantic and sexual relationships.

While research has extensively examined general social support during college, and some attention has been given to social support for heterosexual youth's sexual and relational problems, limited research has examined sexual-minority youth's experiences with social support regarding sexual issues or problems. Sexual-minority youth are almost universally raised in a household with heterosexual parents and the vast majority of their peers are likely heterosexual as well. As a result, there may be important differences in the ways in which sexual-minority and heterosexual youth seek social support for sexual issues from parents and friends. This study examined and compared sexual issues that sexual-minority and heterosexual emerging adult women reported having discussed with friends and parents. This study also assessed potential differences in the sources of social 
support and perceived helpfulness of the support received from these sources. As such, the results of this study shed light on the difficulties sexualminority and heterosexual young adults face in their sexual development and the more or less supportive role parents and friends play in their sexual development. In the following paragraphs, we will first discuss the unique needs of and sources of support for sexual-minority youth during college and then review general patterns of sexual communication with friends and parents during adolescence and emerging adulthood. We will then combine these discussions to present the goals for our study.

\section{Support for Sexual-Minority Youth}

For both heterosexual and sexual-minority youth, social support in college is related to identity development and well-being (Friedlander, Reid, Shupak, \& Cribbie, 2007). General social support plays an important role in adjustment and risk-taking behavior for sexual-minority youth (Vincke \& Van Heeringen, 2002) and social support from friends appears to play an equally important role in sexualminority youth's well-being (Nesmith, Burton, \& Cosgrove, 1999; Ueno, 2005; Weston, 1991). Sexualminority youth likely undergo unique experiences related to their sexuality that can lead to differential experiences with social support. In particular, support for sexual-minority youth's sexual orientation identity has been shown to be associated more closely with well-being than other forms of social support (Beals \& Peplau, 2005). Parental acceptance and social support is also related to a variety of outcomes, including self-esteem, life satisfaction, and depression (Luhtanen, 2003; Mohr \& Fassinger, 2003).

Sexual-minority youth's experiences of social support from parents and friends are unique in several ways from their heterosexual counterparts, namely in that they may need to reveal their sexualminority identification in order to receive appropriate support. Since stigma concerning sexual-minority status may keep many youth from coming out to friends or parents, it is likely that sexual-minority youth may experience less social support than do heterosexual youth (Cain, 1991; Lasser \& Tharinger, 2003). Conversely, sexual-minority youth who are out to friends and families report more social support, higher self-esteem, and less anxiety (D'Augelli, Grossman, \& Sparks, 2005; Jordan \& Deluty, 1998; Vincke \& Van Heeringen, 2002). Because sexualminority youth are more likely to be out to their mother than their father (D'Augelli et al., 2005; Savin-Williams \& Ream, 2003), it is likely that they may seek more support from mothers because of their ability to talk openly about their sexual identity in the context of this relationship.

Social support from friends may also serve several unique functions for sexual-minority youth. Nonfamily members are perceived to be more supportive to sexual-minority youth than family members at this developmental period (Nesmith et al., 1999). Also, although being out is related to more support from parents, youth who are out have reported a greater increase in social support from friends than from parents (Jordan \& Deluty, 1998). While both parents and friends can provide emotional and informational support, friends can also provide other unique forms of support. This is especially true of sexual-minority friends (Ueno, 2005). For example, gay, lesbian, and bisexual friends can help sexual-minority youth gain entrance into queer communities (Nesmith et al., 1999). LGBTQ communities can be important sites of development and support. Sexual-minority individuals have described such communities as a "family we choose"-a close set of friends who provide significant social support and protect their members from the effects of heterosexism in our society (Weston, 1991).

Supportive friends and parents may be especially important for sexual-minority youth due to their frequent experiences with heterosexist discrimination (D'Augelli, 2003; Herek, Gillis, Cogan, \& Glunt, 1997). Research suggests that women (Ayres, Friedman, \& Leaper, 2008; Foster, 2000) and sexual minorities (Leets, 2002) often seek and receive emotional support and practical advice after an experience with discrimination. The level of perceived social support available has also been related to sexual orientation identity for gay males (Elizur \& Ziv, 2001), such that sexual-minority participants with more integrated sexual identities report higher levels of support than those with less established sexual identities.

Overall, research has found that social support from friends and parents can be important for sexualminority youth's general and sexual development. Research has also suggested several aspects of sexual-minority individuals' experiences that contribute to potentially unique forms of social support within these interpersonal relationships. However, further research is needed to understand the role of social support for sexual issues in emerging adults' sexual development and to better 
understand the ways in which sexual-minority youth's experiences of social support from parents and friends might differ from their heterosexual counterparts.

\section{Conversations with Parents and Friends about Sexuality}

Research with predominantly heterosexual youth suggests that conversations concerning sexuality with friends and parents are an important context for sexual development (Aspy, Vesely, Oman, Rodine, Marshall, \& McLeroy, 2006; Downie \& Coates, 1999; Lefkowitz \& Espinosa-Hernandez, 2007; Wood, Senn, Desmarais, Park, \& Verberg, 2002). However, this research has not emphasized sexual issues or problems and subsequently has not explored sexual communication as a form of social support. Instead, much of this research has identified general topics of communication as well as behavioral outcomes of sexual communication patterns with parents and friends (DiIorio, Pluhar, \& Belcher, 2003; Lefkowitz \& Espinosa-Hernandez, 2007; Wood et al, 2002). Youth have reported discussing a variety of topics related to sexuality with their parents; common issues include sexual health issues such as contraception and condom use, sexually transmitted infections, pregnancy, and menstruation. Parents and adolescents also report discussing abstinence and delaying sex until marriage, dating, sexual intercourse, and choice of sexual partners (DiIorio, Kelley, Hockenberry-Eaton, 1999; Schouten, van den Putte, Pasmans, \& Meeuwesen, 2006). Importantly, research suggests that the frequency of discussions about sexuality and the issues that are discussed differ between white and minority families (Guilamo-Ramos, Dittus, Jaccard, Goldberg, Casillas, \& Bouris, 2006; Kim \& Ward, 2007).

Conversations about sexual topics are related to several aspects of youth's sexual development. Youth who report more conversations with parents on the topics of delaying sex and birth control engage in lower rates of sexual risk-taking (Aspy et al, 2006). However, research has suggested that discomfort experienced by parents and their adolescents in speaking about adolescent sexuality can prevent effective sex education from occurring (GuilamoRamos et al., 2006; King \& Lorusso, 1997). Overall, research has established complex, but persistent, associations between parent-child communication about sexuality and adolescents' and young adults' sexual behaviors.
Youth also engage in conversations concerning sexuality with friends. Lefkowitz and EspinosaHernandez (2007) found that students in the first semester of college were more likely to discuss dating, fertility, sexual behaviors and desire, birth control, and related issues with friends than with parents. Youth also often report being more comfortable discussing sexual issues with friends than with parents (Halpern-Felsher, Kropp, Boyer, Tschann, \& Ellen, 2004; DiIorio et al., 1999; Lefkowitz \& Espinosa-Hernandez, 2007) and rate these conversations with friends as high in quality (Lefkowitz, Boone, \& Shearer, 2004). Sexual communication with friends may be more strongly related to sexual development than sexual communication with parents. Conversations about sex with friends appear to be more predictive of sexual attitudes and contraception knowledge than conversations with parents (Halpern-Felsher et al., 2004; Lefkowitz \& Espinosa-Hernandez, 2007; Treboux \& Busch-Rossnagel, 1990). Whereas conversations with parents are often related to lower rates of sexual activity, youth who are sexually active are more likely to report sexual communication with friends than those who are not sexually active (Dilorio et al., 1999; Lefkowitz \& EspinosaHernandez).

Notably, research has identified consistent gender differences in the rates in which youth discuss sexual topics with their parents. Daughters are more likely to report engaging in conversations about sexuality with their parents than are sons (Schouten et al., 2006). Furthermore, whereas messages to sons sometimes promote sexual exploration and pleasure (Downie \& Coates, 1999; Moore \& Rosenthal, 1991), daughters are more likely to receive protective or restrictive messages concerning sex (Downie \& Coates; O'Sullivan, Meyer-Bahlburg \& Watkins, 2001). Mothers report discussing abstinence, sexually transmitted infections, and pregnancy more frequently with daughters than with sons (GuilamoRamos et al., 2006). The rates and quality of sexual communication also depends on the gender of the parent. Young women also often report feeling more comfortable talking with mothers about sexual issues than talking with fathers (DiIorio et al., 1999) and Asian-American daughters have reported higher rates of sexual discussions with mothers than fathers (Kim \& Ward, 2007).

Several gender-related patterns have also been identified between young men and women's sexual communication with same-sex friends. For example, women in emerging adulthood may be more likely 
than men to discuss sexual issues with friends (Lefkowitz et al., 2004). More specifically, women are more likely to discuss dating, fertility, and abstinence than men. In contrast, men were more likely to discuss sexual behavior and desire (Lefkowitz \& Espinosa-Hernandez, 2007). Overall, the gender differences present between young women and men regarding sexual communication with parents and friends suggest a need to provide a separate analysis for men and women. As such, we have chosen to examine sexual-minority and heterosexual women's experiences seeking social support for sexual issues from parents and friends.

In sum, sexual communication with friends and parents is commonly portrayed as a method of sharing sexual information or attitudes and is understood to be integral to adolescents' sexual development. Previous research has also found that social support is related to identity development and well-being for sexual-minority and heterosexual youth. However, little research has examined sexual communication as a form of social support, despite the fact that these conversations may include discussions of difficulties with romantic relationships, sexual health, and a variety of other related sexual issues. In addition, this body of research has done little to identify the potentially unique experiences of sexual-minority youth regarding discussion with parents or friends about sexual issues, despite research that suggests the important function of general social support for sexual-minority youth during this developmental period.

\section{Current Study}

The current study examined social support for sexual issues as a site for sexual identity development. We explored and compared sexual-minority (including individuals identifying as gay/lesbian, bisexual, queer, and "other") and heterosexual young women's reports of seeking social support from friends and parents about sexual issues. More specifically, we analyzed self-report event narratives about a time the participant approached a parent and a time the participant approached a friend for social support about an issue related to their sexuality. Because few studies have explored young women's experiences of seeking social support for sexual issues and little attention has been given to sexual-minority women's potentially unique experiences talking with parents and friends about sexuality, we chose to use openended qualitative responses to explore this topic and optimize our ability to represent participants' experiences.

There were four primary goals for this study. First, we investigated reports of seeking support, which included analyzing whether women report seeking support more often from friends or parents and whether this differs for sexual-minority and heterosexual participants. Based on prior research, we anticipated that not all participants will report seeking support for sexual issues from parents and friends (DiIorio et al., 1999; Lefkowitz \& EspinosaHernandez, 2007). In particular, we hypothesized that sexual-minority women may be less likely than heterosexual women to report an experience with social support for sexual issues due to difficulties coming out to friends and family (Cain, 1991; Lasser \& Tharinger, 2003). We also anticipated that both heterosexual and sexual-minority women would report seeking support about sexual issues from both parents and friends, but more often from friends (e.g., Lefkowitz \& Espinosa-Hernandez, 2007). Second, we examined demographic characteristics of the sources of social support, including the gender of the parent or friend and the sexual orientation of the friend from whom the participant reported seeking support, to shed light on which relationships are important contexts for sexual development. Because prior research has found that young women typically report communicating with mothers more than fathers about sexual topics (e.g., Dilorio et al., 1999), we anticipated similar patterns for our participants. Additionally, because LGBTQ friends can be important sources of support for sexual-minority youth (e.g., Ueno, 2005), we anticipated that sexualminority participants would report seeking support from LGBTQ friends. Third, we conducted a thematic review of the reported sexual issues and examined how each issue related to the source of support (parent or friend) and the participants' sexual orientation. This research question allowed us to explore what sexual issues face young sexualminority and heterosexual women. Lastly, we explored how helpful participants found these conversations. Again, we examined differences and similarities between sexual-minority and heterosexual women's accounts of seeking social support from friends and parents.

\section{Method \\ Participants \\ Participants were recruited through introductory psychology classes at a university in central}


This is an author-produced, peer-reviewed version of this article. The final, definitive version of this document can be found online at Journal of Youth \& Adolescence (doi: 10.1007/s10964-008-9361-0) published by Springer. Copyright restrictions may apply.

California and from LGBTQ centers at several universities across California. Email notices, fliers, and information on the websites of these LGBTQ centers explained that the study was about the experiences of lesbian, bisexual, and queer women enrolled in college and included a link to a secure online survey website. Participants were also asked to inform their friends of the study. Participants received partial course credit or a $\$ 10$ gift certificate to an online retailer for participating.

The sample consisted of 229 women between the ages of 18 and $25(M=19.64, S D=1.34)$. The participants represented a range of ethnic backgrounds: European-American (62\%), AsianAmerican (15\%), Latina (11\%), Black/AfricanAmerican (3\%), and nine percent of participants reported a mixed or "other" ethnicity. All of the participants were currently enrolled in college or had graduated within the past nine months. Thirty percent of participants were first year students, $31 \%$ were sophomores, $25 \%$ were juniors, $10 \%$ were seniors, and $4 \%$ were fifth year, sixth year, or recently graduated.

Their self-identified sexual orientations included heterosexual $(n=142,61 \%)$, gay/lesbian $(n=17$, $8 \%)$, bisexual $(n=42,18 \%)$, and queer $(n=17,8 \%)$. Eleven women choose the "other" category and identified as bicurious $(n=3)$, questioning $(n=2)$, fluid $(n=1)$, pansexual $(n=1)$, heterosexual/curious/ bisexual $(n=1)$, whatever I feel like $(n=1)$, heterosexual who sleeps with women $(n=1)$, and I don't label myself $(n=1)$. All women who identified as anything but heterosexual were placed in the sexual-minority category, as previous research has found differences between women who identify as exclusively heterosexual and those who do not identify as exclusively heterosexual (Thompson \& Morgan, 2008). Furthermore, bisexual, lesbian, and queer women were placed in the same category as there were no significant differences in age or any outcome variables between the three groups. This yielded a sample of 88 sexual minority women and 141 heterosexual women. Out of the 88 sexualminority participants, $53 \%$ reported that neither parent was aware of their sexual orientation and $12 \%$ indicated that none of their close friends were aware of their sexual orientation. Sexual orientation status was not associated with age or race/ethnicity (both p's >.05).

\section{Procedures}

Participants completed the questionnaire through a secure, online website. The website provided participants with information about the study, after which participants indicated consent by typing their name on the first page. The first part of the questionnaire consisted of a series of demographic questions that inquired about the participants' sexual orientation, ethnicity, age, and number of years in college. Sexual-minority participants were also given a measure of sexual orientation disclosure, which included two questions regarding how many of their close friends and how many of their family members were aware of their sexual orientation. Participants responded to these questions using a 5-point Likert scale $(1=$ None, $3=$ About half, $5=$ Everyone $)$. Participants were then provided with unlimited space to answer the open-ended experiences with social support measure. Participants also completed additional measures that were not analyzed for the current study. The entire questionnaire took approximately 45 minutes to complete.

Measures

The measure of experiences with social support included two sets of open-ended questions that inquired about participants' experiences with social support from friends and parents about issues related to their sexuality. The questions were prefaced with instructions for participants to answer as completely and as detailed as possible. The first set of questions inquired about social support from friends and asked, "Please describe a recent time you went to your friends for support for an issue related to your sexuality." Participants were then asked to explain the problem, who they asked for support, what kind of support they received, and why they did or did not find the support they received helpful. Next, an identical set of questions inquired about a time that participants had approached their parents for social support for an issue regarding their sexuality. Again, the first question asked, "Please describe a recent time you went to your parents for support for an issue related to your sexuality."

All responses to the experiences with social support measure were coded by the first author and a female research assistant. Coders were blind to participants' demographic information, including self-identified sexual orientation. Disagreements were discussed until a consensus was reached. Information on the coding categories and reliability analyses are detailed below. 
Sources of support. In order to gain more specific information about the people that participants reported having approached for social support, we coded for both the gender of the friend and parent. The gender of friends and parents were coded as male, female, and both (i.e., mother and father). Forty-eight participants did not specify the gender of the friend; these responses were labeled as "unable to code." Acceptable reliability was obtained between coders for both the gender of the friend(s) $(\kappa=.91)$ and the gender of the parent(s) $(\kappa=.98)$.

Because 23 of the participants mentioned the sexual orientation of the friend who offered support, sexual orientation of friends was coded as well. Sexual orientation of friends was coded as heterosexual, LGBTQ, both, or unable to code. An example of a response that received the code "LGBTQ" is from a 20-year-old queer-identified woman who explained that she "asked another queer female friend of mine" for suggestions dealing with a dating relationship. An example of a response coded for "both" is from a heterosexual-identified woman who explained: "I just tell my two closest friends (one is a gay male, the other is a heterosexual female) that I am lonely and really want a guy in my life." Only responses who specifically described a friend as heterosexual or LGBTQ were coded. In other words, if the participant did not directly indicate their friends' sexual orientation, the response was coded as "unable to code." Acceptable reliability was obtained on this category $(\kappa=.91)$.

Issues discussed. Thematic analysis (Braun \& Clarke, 2006) was used to investigate the problems or issues participants reported as the reason for seeking support from friends and parents. All responses were reviewed multiple times by the authors and compiled into groups based on the type of problem discussed. Five types of issues were identified from these inductively developed groups. These issues were labeled: dating and relationships, sexual behavior, sexual health, identity negotiation, and discrimination and violence. Because we asked participants to describe one specific instance in which they approached a friend or parent for support, responses included only one issue. Thus, types of issues were mutually exclusive categories, such that each problem discussed was classified as only one issue type. Interrater reliability for the five types of issues was adequate for issues discussed with friends $(\kappa=$ $.87)$ and parents $(\kappa=.91)$. Definitions and examples of each type of issue can be found in Table 1.
Perceptions of support as helpful. Lastly, we coded whether participants perceived the social support they received as helpful. Many women clearly described the support they received as helpful or not helpful. Other responses indicated that the participant felt that while the support was helpful in some ways, it was not as effective as they would have liked. For example, a 22-year-old lesbian-identified woman recounted a time she asked one of her friends about meeting other lesbian women. She was ambivalent about the friends' suggestions: "Her advice about going out to queer events and out to queer bars were helpful, but after I had cut my hair, I had realized that it was for the wrong reasons and therefore, regreted chopping it all off." To represent responses such as this, we had three coding categories: not helpful, mixed, and helpful. Acceptable reliability was obtained for coding the helpfulness of support from friends $(\kappa=.86)$ and parents $(\kappa=.94)$.

\section{Results}

\section{Reports of Receiving Social Support}

Not all of the women who responded to the "Experiences with social support" measure provided a narrative of a time that they went to their parents or friends for social support. As expected, many women responded that they could not recount a time that they discussed a sexual issue with parents and/or friends. Fifty-one percent of women $(n=117)$ responded that they had never gone to a parent for support about a sexual issue and 20 percent of women $(n=46)$ responded they had never gone to a friend for support about a sexual issue. There were no differences between women who did report an instance of social support for sexual issues and those that did not in age or sexual orientation, both $p$ 's $>.05$.

Although we did not include a prompt for women to explain why they may not discuss sexual issues with their friends or parents, many who noted not going to parents or friends for support did so anyway. The most commonly cited reason for not discussing sexual issues with parents or friends was that it would make family and friends uncomfortable to discuss the issue or that they would not understand. Many ethnicminority women cited communication difficulties or cultural differences between themselves and their parents as the reason that they were not comfortable approaching their mother or father. For other women, it was the traditional views of their parents or friends that kept them from receving social support, such as one 18-year-old heterosexual-identified woman who wrote: "My friends are pretty conservative so we 
don't usually talk about these issues." Finally, many sexual-minority women referred to their friends' and parents' inability to accept their sexual orientation as the reason they had not received social support. One 19-year-old queer-identified woman explained,

I don't ever talk about my sexuality with my parents. Only when I came out to them. Definitely not for support on an issue, more like a problem that they have. For example my mother is a little uncomfortable with me actually having a girlfriend but she doesn't mind that I'm queer.

All of the following analyses were conducted with participants who provided an event narrative $(N=$ 199). First, analyses were conducted to assess whether participants were more likely to report having approached a friend, a parent, or both. Analyses indicated that participants were more likely to report seeking support from both parents and friends $(46 \%)$ than only from friends $(34 \%) \chi^{2}(1, N=$ $183)=4.59, p=.03$, or only from parents $(3 \%), \chi^{2}(1$, $N=112)=89.28, p<.001$. Additionally, participants were more likely to report seeking support only from friends $(34 \%)$ than only parents $(3 \%), \chi^{2}(1, N=83)$ $=60.73, p<.001$. There was no difference in heterosexual and sexual-minority women's reports of seeking support from friends, parents or both parents and friends, both $p$ 's $>.05$.

Second, analyses were conducted to examine whether sexual-minority women who reported seeking support from parents or friends scored higher on the measure of sexual orientation disclosure to close friends and family members. Sexual-minority women who reported seeking support from parents were out to more members of their family $(\mathrm{M}=2.49, \mathrm{SD}=$ 1.46) than sexual-minority women who did not report seeking support from parents $(\mathrm{M}=1.60, \mathrm{SD}=1.05)$, $\mathrm{t}(82)=-2.23, \mathrm{p}=.02$. Also, sexual-minority women who reported seeking support from friends were out to more friends $(M=4.10, S D=1.10)$ than sexualminority women who did not report seeking support from friends $(\mathrm{M}=2.93, \mathrm{SD}=116), \mathrm{t}(82)=-3.69, \mathrm{p}<$ .001 .

\section{Sources of Social Support}

The next set of analyses explored if parents' gender, friends' gender, and friends' sexual orientation were important demographics regarding who sexualminority and heterosexual women went to for support about sexual issues. Both gender and sexual orientation appeared to be important factors in who women approached. The 112 women who reported seeking support from parents were more likely to report going to their mother $(71 \%)$ than their father (7\%), $\chi^{2}(1, N=112)=21.54, p<.001$, or both parents $(20 \%), \chi^{2}(1, N=112)=72.36, p<.001$. The 193 participants who reported going to a friend for support were more likely to recount an instance in which they talked with female friends $(61 \%)$ than male friends $(8 \%), \chi^{2}(1, N=193)=23.91, p<.001$, or both female and male friends $(5 \%), \chi^{2}(1, N=193)$ $=14.93, p<.001$. These results did not differ for sexual-minority or heterosexual participants (all $p$ 's $>$ $.05)$.

Sexual-minority women differed from heterosexual women regarding the reported sexual orientation of the friends they approached for social support. Specifically, sexual-minority women (20\%) were more likely than heterosexual women $(0 \%)$ to report seeking help from LGBTQ friends, $\chi^{2}(1, N=199)=$ $26.43, p<.001$. Heterosexual women $(94 \%)$ were more likely than sexual-minority women $(72 \%)$ to report seeking support from friends without citing their sexual orientation, $\chi^{2}(1, N=199)=18.55, p<$ .001 . Sexual-minority and heterosexual women were equally likely to report seeking support from heterosexual friends and both heterosexual and sexual-minority friends (both $p$ 's $>0.05$ ).

In addition to seeking support from other sexualminority friends, four sexual-minority women also specifically reported having received support from LGBTQ student organizations or LGBTQ support groups. A 20-year-old lesbian-identified woman described finding people she could relate with at "a student support group specifically for queer people of color" when she was questioning her sexual orientation. Another 22-year-old who identified as "fluid" reported going to her school's LGBTQ resource center for help on coming out to her parents. She reported that her friends at the center gave her "many different stories, pieces of advice and comfort... It was very helpful at least in helping my emotional state."

\section{Sexual Issues}

As outlined previously, sexual issues discussed with friends and parents were inductively grouped into five categories: dating and relationships, sexual behavior, sexual health, identity negotiation, and discrimination and violence. Of the 193 participants who described seeking support from a friend, $48 \%$ ( $n$ $=92$ ) described a sexual issue pertaining to dating 
and romantic relationships, $18 \%(n=35)$ described an issue pertaining to sexual behavior, $5 \%(n=10)$ described an issue pertaining to sexual health, $21 \%(n$ $=40$ ) described an issue pertaining to identity negotiations, $8 \%(n=15)$ discussed an issue pertaining to discrimination and violence, and one participant reported an experience that was coded as "unable to code." Of the 112 participants who described seeking support from a parent, 37\% ( $n=$ 41) described an issue pertaining to dating and romantic relationships, $9 \%(n=10)$ described an issue related to sexual behavior, $25 \%(n=28)$ described an issue pertaining to sexual health, 19\% ( $n$ $=21$ ) described an issue pertaining to identity negotiations, 9\% $(n=10)$ described an issue pertaining to discrimination and violence, and two participants reported an experience that was coded as "unable to code."

One-way ANOVA's were conducted to examine the association between participants' age and the five types of sexual issues discussed with friends and parents; these results indicated that age was not related to which sexual issues were reported (both $p$ 's $>$.05). As a result, age was not included in further analyses. In the following section, Pearson's goodness-of-fit chi-square analyses with assumptions of response equality were conducted to examine whether each sexual issue was more likely to be raised with a friend, a parent, or both. Additionally, chi-square analyses were used to ascertain whether sexual-minority or heterosexual participants were more likely to report seeking help for each issue. These chi-square statistics are reported in Table 2 along with the percentages of sexual-minority and heterosexual women who reported discussing each sexual issue with parents and friends. Lastly, we include further detail of each sexual issue using qualitative descriptions and representative example narratives.

Dating and relationships. When examining the 107 participants who mentioned this issue, the overall chi-square assessing differences in seeking support from parents, friends, or both parents and friends indicated significant differences in the source of support, $\chi^{2}(2, N=107)=40.39, p<.001$. Follow-up chi-square analyses revealed that participants were more likely to report going to friends only (63\%) about dating and relationships issues than to parents only $(14 \%), \chi^{2}(1, N=81)=32.11, p<.001$, or to both parents and friends $(24 \%), \chi^{2}(1, N=92)=$ 17.39, $p<.001$. Additionally, participants were marginally more likely to go to both friends and parents than parents only, $\chi^{2}(1, N=41)=2.95, p=$ .09 .

To examine differences between sexual-minority and heterosexual women in reporting this theme, analyses were conducted with the 199 participants who recounted an instance in which they received support from friends and family. Heterosexual participants (25\%) were marginally more likely to discuss dating and romantic relationships with parents than were sexual-minority participants $(14 \%), \chi^{2}(1, N=199)=$ $3.57, p=.06$. Heterosexual participants were also significantly more likely to report discussing this issue with friends $(24 \%)$ than were sexual-minority participants $(7 \%), \chi^{2}(1, N=199)=9.02, p=.03$.

Sexual-minority and heterosexual women's discussions of sexual issues about dating and romantic relationships were similar in several ways and also revealed some unique experiences for the sexual-minority participants. Both sexual-minority and heterosexual women described going to friends and parents about wanting a boyfriend or girlfriend, questions about whether they should date a specific person, and breaking up with romantic partners. Both groups also discussed needing support for issues within current romantic relationships. For example, a 21-year-old heterosexual woman described approaching her best friend from high school because her "boyfriend does not provide as much interest in intimacy as needed." A 20-year-old queer-identified woman also described talking with a friend when she "was upset because my girlfriend was emotionally distant."

Another common problem within this category included the difficulties associated with "hooking up" with a close friend without endangering the prior friendship. In many of these recollections, participants discussed worrying that sex would cause them to lose a friendship that was important to them or would allow them to get hurt emotionally. For example, a 20-year-old queer-identified woman received advice from her roommates and friends for a confusing relationship with another friend:

My best friend (whom has always identified as mostly straight/only dated men) made romantic passes at me, and we then began to sleep together. I was having a difficult time... especially considering the fact that I identify as a lesbian and she did not, so continuing our sex together could open me up to be hurt in the long run. 
A 19-year-old heterosexual-identified woman recounted going to her friends and her mother for a similar issue:

A boy I had been sexually involved with (in a kind of exclusive friends with benefits situation that had turned into something on the boarder of a romantic relationship) who had moved away several months prior was coming back to visit and wanted to have sex and I was unsure whether I could handle that emotionally.

Despite the similarities that emerged between sexualminority and heterosexual women's narratives about dating and romantic relationship issues, there were also notable differences in their experiences. One was the difficulty sexual-minority women described in meeting same-sex romantic partners. Many recounted going to their friends for advice on how to meet other queer women in college or while attending queer events. In many cases, it seemed that college provided them with new dating possibilities but they were uncertain on how to best take advantage of these opportunities. For example, a 23-year-old bisexual-identified woman described why she went to her friends for support: "I am very shy and so I was weird about meeting other queer people at school where I had just transferred and wasn't sure what to do." Another unique experience for sexual-minority women was when women they were interested in or dating chose to participate in heterosexual relationships or were questionning their sexual orientations. In particular, participants discussed needing social support when a crush got a boyfriend, such as an 18-year-old lesbian-identified woman who explained that she went to her queer friends when, "the girl I am in love with, who every one thought was into me, started dating the boy who is the jackass of my Adventure Scouts Troop."

Sexual behavior. The overall chi-square analysis assessing differences between the 39 participants who mentioned this theme in seeking support about sexual behavior from parents, friends, or both parents and friends indicated significant differences in the source of support, $\chi^{2}(2, N=39)=29.69, p<.001$. Follow-up analyses revealed that participants were more likely to report going to friends only (74\%) about sexual behavior issues than to parents only $(10 \%), \chi^{2}(1, N=33)=18.93, p<.001$, or to both parents and friends $(15 \%), \chi^{2}(1, N=35)=15.11, p<$ .001. There was no difference between participants' reports of seeking support from parents only or both friends and parents, $p>.05$.

Additional analyses were conducted with the total sample of 199 participants who reported receiving support about a sexual behavior issue from friends and parents to examine differences between sexualminority and heterosexual participants. Heterosexual participants $(7 \%)$ were more likely to discuss sexual behavior with parents than sexual-minority participants $(1 \%), \chi^{2}(1, N=199)=3.88, p=.04$. Heterosexual participants were also more likely to report discussing this issue with friends (24\%) than sexual-minority participants $(7 \%), \chi^{2}(1, N=199)=$ 9.02, $p=.003$.

Sexual-minority and heterosexual women described somewhat different types of sexual behavior issues. In general, sexual-minority women were less likely to discuss sexual behavior with both parents and friends, and when they did, it often pertained to heterosexual sex. For example, a 20-year-old bisexual-identified woman reported receiving oral sex performance techniques from her best friend: "I once asked my friend how to give better blowjobs because it seemed like it took way too long for my sex partners to come." Only two sexual-minority women approached a friend for advice for sex with women. A 21-year-old lesbian-identified woman told a friend from high school that: "I felt extremely uncomfortable about sex at one point, and worried that if I ever started having it with another woman, I'd be horrible at it." Her friend suggested some books on the subject, although she reported that she never followed up with the advice. Similarly, a 23-year-old queer-identified woman recounted a time she talked with a friend about having sex with a woman:

I didn't really know how to have sex with a woman. I had done so in the past, but most of the situations where while drunk or one night stands. I was worried that I wouldn't be any good while in a relationship. Its the same mechanics and all but I was really scared I wouldn't know what to do.

Similar to the sexual-minority participants, a common issue among heterosexual women was seeking tips for increasing their own or their partners' satisfaction with sex. However, heterosexual women also reported discussing a variety of other issues related to sexual desire and behavior with their friends. For example, they reported discussing being sexually active, sharing personal stories about their 
experiences, and receiving advice concerning participating in threesomes and other sexual experimentation.

Sexual health. The overall chi-square assessing differences in seeking support about sexual health from parents, friends, or both parents and friends between the 35 participants who included this theme indicated significant differences in the source of support, $\chi^{2}(2, N=35)=25.54, p<.001$. Follow-up analyses revealed that participants were more likely to report going to parents only $(71 \%)$ about sexual health issues than to friends only $(20 \%), \chi^{2}(1, N=$ $32)=10.12, p=.001$, or to both parents and friends (9\%), $\chi^{2}(1, N=28)=17.28, p<.001$. There was no difference between participants' reports of seeking support from friends only or both friends and parents, $p>.05$.

Analyses were also conducted with the sample of 199 participants who reported receiving support from friends and parents for sexual health issues to examine differences between sexual-minority and heterosexual participants. Heterosexual participants (20\%) were more likely to discuss sexual health with parents than were sexual-minority participants $(5 \%)$, $\chi^{2}(1, N=199)=8.79, p=.003$. Heterosexual participants were also more likely to report discussing this issue with friends $(8 \%)$ than were sexual-minority participants $(0 \%), \chi^{2}(1, N=199)=$ $6.93, p=.008$.

Similar to issues about sexual behavior, sexualminority participants were less likely than their heterosexual counterparts to discuss issues of sexual health. However, heterosexual women reported seeking more support regarding sexual health from parents (typically mothers) than friends. Topics that many women reported discussing with their mothers included sexually transmitted infections (STIs) and birth control. In particular, participants frequently reported that their mothers helped them pay for birth control or treatment for STIs. One 21-year-old heterosexual-identified woman discussed the following issue with her mother, "The problem was birth control and not knowing whether to go off of it because of the effects of the hormones on my emotional state and my body. Also gynecology appointments and when my next one should be." When women discussed sexual health with their friends, their conversations often concerned sexual difficulties such as pain during sex or an inability to orgasm. One 21-year-old heterosexual-identified woman asked her friends for help because, "When my boyfriend and I try to have sex it hurts me too much for him to go in all the way, or it just doesn't seem to work."

Identity negotiation. The overall chi-square assessing differences in seeking support about identity negotiation from parents, friends, or both parents and friends indicated significant differences in the source of support, $\chi^{2}(2, N=51)=14.94, p=.001$. Followup analyses revealed that participants were more likely to report going to friends only (59\%) about identity negotiation issues than to parents only $(22 \%), \chi^{2}(1, N=41)=8.80, p=.003$, or to both parents and friends $(19 \%), \chi^{2}(1 N=40)=10.00, p=$ .002 . There was no difference between participants' reports of seeking support from parents only or both friends and parents, $p>.05$.

Additionally, analyses were conducted with the sample of 199 participants who reported receiving support from friends and parents to examine differences between the number of sexual-minority and heterosexual participants who reported an identity negotiation issue. Sexual-minority participants $(20 \%)$ were more likely to discuss identity negotiation with parents than heterosexual participants $(4 \%), \chi^{2}(1, N=199)=13.06, p<.001$. Sexual-minority participants were also more likely to report discussing this issue with friends (39\%) than heterosexual participants $(7 \%), \chi^{2}(1, N=199)=$ $29.88, p<.001$. In contrast to previous issues, young sexual-minority women were more likely than heterosexual women to receive support for identity negotiation.

Sexual minority women's responses regarding identity negotiation differed in several important ways from heterosexual women's responses. Namely, unlike heterosexual women, identity negotiation was the most frequent sexual issue sexual-minority women reported discussing with either parents or friends. Responses included discussing the importance of appearance within the queer community (such as hair length) and definitions or redefinitions of what it means to be queer. One of the most common issues within this theme was coming out to parents and friends. In some cases, participants discussed parents' or friends' acceptance as a form of social support. Other women reported asking others for advice on how to come out or how to hide their identity from parents. For example, one 21-year-old lesbian-identified woman reported getting support from her mom after inadvertently coming out to her dad: 
I was already out to my mom for a few years, but not my dad. My dad lives in another state, so I never thought he'd figure it out. But one day he found my myspace account and saw my sexual orientation listed. He called me up on the phone and started talking to me in this icy cold tone of voice and making me feel very uncomfortable. He said my sexual orientation didn't matter to him, but I felt like it really did. It upset me a lot.

This participant's mother sympathized with her, which the participant reported being very grateful for: "She talked about how clueless and tactless my dad was, and I think she even called him up later and yelled at him."

Although only two sexual-minority women discussed dating a transgendered individual, these relationships emerged as spaces for significant redefinition of queer identity. One of these participants, a 20-yearold queer-identified woman explained, "I was dating someone $\mathrm{mtf}$ trans but who was not planning to transition for a long time. As I am mostly attracted to women, sex proved fairly problematic and was putting strain on our relationship." It is clear that this woman was facing identity and sexual issues within her relationship. Another participant, a 21-year-old queer-identified woman, confronted similar issues:

I was recently dating a transman and was having a really hard time with the fact that our relationship looked really heteronormative (he passed flawlessly). I was feeling like my "queerness" was being erased by a seemingly "normal" heterosexual relationship.

She continues to write that although she found support from other queer-identified women who were dating transmen, it "didnt necessarily keep me from feeling uncomfortable about telling people I was dating a 'he'."

Identity issues also arose as sexual-minority participants considered the implications of being attracted to or being sexually involved with men. For example, one 20-year-old queer-identified woman recounted talking with her best friend about being attracted to a boy but unsure whether to date him: "I was really attracted to a guy but I had wanted to explore my queer side more." Similarly, an 18-yearold lesbian-identified woman had sex with a male friend as a way to test whether she still enjoyed sex with men. She described the advice she got from a close gay male friend:

He told me it was okay, but not to leave such a big descision up to someone who doesn't even know it. And he told me that if I didn't like it, it was okay to finally admit being a lesbian and not just bisexual.

Both of these women used their dating and sexual experiences-as well as the support they received from their friends-as an opportunity to explore and possibly redefine their sexual orientation identity.

It is important to note that collectively 11 percent of heterosexual women reported going to their friends and parents with questions they had concerning their sexual orientation identity. Similarly to sexualminority participants, heterosexual women reported discussing their level of attraction to men and women and difficulties in labeling their orientation with both parents and friends. Some women recounted that questions arose about their orientation because they had not started dating. For example, one 19-year-old heterosexual-identified women reported, "My parents questioned my sexuality because although I do like boys, I don't usually bring them home and they were curious why that was." Other participants reported questioning their identity after having a woman express interest in them. Another 19-year-old heterosexual-identified women explained that, "My female friend had a crush on me, admitted her love to me, which made me question my own sexuality."Overall, there was less variety in the kinds of identity issues heterosexual women discussed compared to sexual-minority women.

Discrimination and Violence. The overall chi-square assessing differences between the 18 participants who mentioned this theme in seeking support about sexual health from parents, friends, or both parents and friends was not significant, $p>.05$. The analyses conducted with the 199 participants who reported support from friends and family suggested that there was no difference between sexual-minority participants' (7\%) and heterosexual participants'(3\%) reports of discussing discrimination and violence with parents, $p>.05$. However, sexual-minority participants were more likely to report discussing this issue with friends $(14 \%)$ than were heterosexual participants $(3 \%), \chi^{2}(1, N=199)=7.66, p=.006$. Similar to the results concerning identity negotiation, sexual-minority women were more likely to report support for discrimination and violence than were heterosexual women. 
Again, sexual minority and heterosexual participants differed in types of problems they discussed that fell within this category. In addition to being less likely to report discussing discrimination with their friends, heterosexual women discussed different forms of discrimination and violence than sexual-minority women. A number of heterosexual women discussed relying on friends and parents for social support concerning abusive relationships or sexual harassment and assault, such as one 19-year-old heterosexual-identified woman who talked with a female coworker and her mother when her male boss started to flirt with her.

In contrast, sexual-minority women almost exclusively discussed heterosexist discrimination with their friends and parents. Many of these women reported receiving support after experiences with discrimination from family or friends. For example, one 22-year-old bisexual-identified woman received emotional support and advice from a friend and her mother about, "My father's expectations of me--his beliefs that I should be in a committed heterosexual relationship at this point in my life." Similarly, an 18year-old bisexual-identified woman reported sharing stories and advice with her friends from the queer community when, "I was having a difficult time with my sister and my high school friends making inappropriate homophobic jokes around me." Fewer women discussed discrimination that they had faced or feared facing from strangers. When they did discuss discrimination from strangers, sexualminority women often expressed anger that they were not able to express affection with other women in public. One 21-year-old lesbian-identified participant described going to her mother after, "some woman came up to my girlfriend and me at the beach and asked us to stop doing what we were doing (just cuddling)."

\section{Perceptions of Support as Helpful}

Participants' evaluations of parents' and friends' responses were coded as not helpful, mixed and helpful. Overall, parents' support was more likely to be perceived as helpful (66\%) than not helpful (18\%), $\chi^{2}(2, N=92)=29.39, N=92, p<.001$, or mixed $(16 \%), \chi^{2}(2, N=89)=33.99, p<.001$. Similarly, support from friends was more likely to be perceived as helpful $(72 \%)$ than not helpful $(9 \%), \chi^{2}(2, N=$ $145)=88.06, p<.001$, or mixed $(19 \%), \chi^{2}(2, N=$ $164)=53.88, p<.001$. Because the three "helpfulness" outcomes occurred along a continuum ( $1=$ not helpful, $2=$ mixed, $3=$ helpful), a paired sample $t$-test was conducted to compare parents' helpfulness to friends' helpfulness. This analysis revealed that friend helpfulness was on average higher $(M=2.67, S D=.06)$ than parent helpfulness $(M=2.48, S D=.79), t(101)=2.21, p=.03$.

Independent sample $t$-tests were used to compare sexual-minority and heterosexual participants' perceived helpfulness of their parents' and friends' responses. Results suggested that sexual-minority women $(M=2.05, S D=.92)$ described the support they received from parents as less helpful than heterosexual women $(M=2.70, S D=.59), t(107)=$ $3.92, p<.001$. Sexual-minority women $(M=2.50$, $S D=.67)$ also described the support they received from friends as less helpful than heterosexual women $(M=2.71, S D=.61), t(178)=2.16, p=.03$.

Though responses from parents and friends were overwhelmingly reported as being helpful, the "mixed" and "not helpful" responses were often likely due to the nature of the sexual issue rather than the parents' or friends' ability to provide support. Many heterosexual and sexual-minority women discussed sexual issues that simply did not have easy solutions. Although friends and parents could give emotional support on issues such as sexual difficulties, problems in finding a partner, or still being a virgin, it was often more difficult to give helpful advice on how to "fix" these problems. The participants seemed to understand this predicament and often described support for these types of issues as mixed, such as this 23-year-old queer-identified woman who talked with her friends about how to have sex with a woman: "It was helpful emotionally. But not technically. I still felt like I had no clue as to what to do. But I was less stressed about not knowing."

Lack of helpfulness for sexual-minority participants was often associated with parents' or friends' lack of understanding or negativity towards sexual-minority populations or the participants' identification as a sexual-minority. More specifically, many sexualminority women expressed that friends and parents did not understand their unique difficulties. Others described parents' and friends' heterosexist hostile responses to their requests for support. For example, one 18-year-old bisexual-identified woman approached her father with concerns about discrimination against the LGBTQ community. Her father did not respond the way she had hoped: 
My father said that the LGBTQ community deserved whatever hate/ discrimination they received because they were a group of minorities that shouldn't exist. I think it should be pretty obvious why I didn't like the "support" I got from my father. Rather, I was shocked at his response and have refused to speak with him on the subject since.

Additionally, in cases where the sexual issue being raised was a participant "coming out" to a parent or friend, sexual-minority women often reported that they did not feel that their coming out resulted in acceptance. Parents were especially likely to react by insisting that their daughter was "going through a phase" or refusing to discuss the matter further. In several cases, parents continued to encourage daughters to date men, especially when the daughter identified as bisexual. One 19-year-old bisexualidentified woman represented this theme in her discussion of coming out to her mother: "Her response was unhelpful because it included telling me to choose partners of the opposite sex whenever it was possible, in order to make my life 'easier.' I should have told her I was a lesbian instead."

\section{Discussion}

The results of this study revealed important information regarding young women's experiences of social support for sexual issues as a site for sexual identity development. For both sexual-minority and heterosexual participants, results suggested that parents and friends are important sources of social support for sexual issues and that their support is generally perceived as helpful. When comparing sexual-minority and heterosexual women's experiences, we found that they differed in who they approached for support and in their reasons for not seeking support from friends or parents. Results also revealed both similarities and differences in the sexual issues that sexual-minority and heterosexual participants discussed with parents and friends. Lastly, results suggest that sexual-minority participants generally reported that the support they received from parents and friends was less helpful than their heterosexual counterparts.

The majority of women in this study were able to recount a time in which they approached a parent or friend for support regarding a sexual issue. Thus, most young women receive support for their sexual development. Friends were by far the more popular source of support overall and on the majority of the sexual issues. In fact, only about half of the participants reported receiving support from parents. This finding coincides with previous research that has suggested that college students discuss sex more with friends than with parents (Lefkowitz \& EspinosaHernandez, 2007). Also extending previous research (Dilorio et al., 2003; Kim \& Ward, 2007), participants were more likely to indicate that relationships with female friends and mothers were especially important contexts for sexual development. Though support from parents and friends was generally perceived as helpful, results also suggested that women were more likely to describe the support they received from friends as helpful compared to support they received from parents. This difference in perceived helpfulness extends previous findings that youth typically report being more comfortable discussing general sexual topics with friends than parents (DiIorio et al., 1999; Halpern-Felsher et al., 2004; Lefkowitz \& EspinosaHernandez).

Results suggested similarities and differences in sexual-minority and heterosexual women's experiences with social support. Despite research suggesting that identifying with a stigmatized group may prevent sexual-minority youth from coming out or experiencing general social support (Lasser \& Tharinger, 2003), sexual-minority women were equally likely as heterosexual women to report an event narrative about seeking support for a sexual issue. However, sexual-minority participants did generally describe the support they received from parents and friends as less helpful than did heterosexual participants. Another important finding regarding the sexual-minority participants is that the sexual-minority women who reported seeking support from parents and friends were more out to their family and peer group, respectively. This finding offers insights into prior research on sexual communication with parents as well as research on the impact on sexual-minority youth of being out to parents and friends. First, parents are more likely to report discussing sexuality with their (heterosexual) daughter when they know that she has dated (Eisenberg, Sieving, Bearinger, Swain, \& Resnick, 2006). If a lesbian, bisexual, or queer daughter is not out to her parents, then it is likely that her parents are not aware of her dating history or status. Second, previous research has found that youth who are out to family and friends report greater well-being (D'Augelli, Grossman, \& Sparks, 2005; Jordan \& Deluty, 1998; Vincke \& Van Heeringen, 2002). While it is possible that heightened well-being among sexual-minority youth who are out to family and 
friends may be related to greater resolution of identity negotiation and being able to date people of the desired gender, it is also possibly partially explained by the increased availability of social support for sexual issues from these informed sources.

Results also indicated that sexual-minority women were more likely to report discussing sexual issues with LGBTQ friends than were heterosexual women. This finding should be interpreted with caution, as we did not directly inquire about the sexual orientation of the friends that participants approached for support. This discrepancy may be to the result of differences in the salience of sexual orientation. Due to heteronormative assumptions, sexual orientation may not be a salient issue for heterosexual women. If their friends are also heterosexual, heterosexual young women likely will not feel the need to make their sexual orientation clear. In contrast, sexualminority women may be more likely to feel that the orientation of their friends is worth noting. This difference may also be due to sexual-minority women's reluctance to approaching heterosexual parents or friends due to discomfort or lack of understanding on the part of the parent or friend. Sexual-minority participants were also more likely to discuss sexual identity and discrimination issues. It is possible that they more often sought support from LGBTQ friends because they felt were likely to understand and be comfortable with their unique issues. These results extend prior findings that friendships with other sexual-minority youth may provide a supportive environment for identity development (Ueno, 2005).

Five sexual issues emerged as reasons why participants had sought social support. Three of the sexual issue topics that emerged are comparable to research on general communication with parents and friends; these include dating and romantic relationships, sexual behavior, and sexual health (DiIorio et al., 1999; Schouten et al., 2006). In general, participants were more likely to seek support for romantic relationships and sexual behavior from friends than from parents. These findings coincide with past research that has found that youth are more hesitant to discuss sexual behavior with parents than friends (e.g., Halpern-Felsher et al., 2004) and may seek more support from friends concerning relationships because they are less judgmental about participants' choices. In contrast, youth were more likely to report seeking support concerning sexual health from parents than from friends. Young women may perceive parents as more knowledgeable on issues concerning sexual health. Parents may also see communication on sexual health as a way to protect their daughters from unwanted pregnancies and STIs and therefore be more open to this topic of discussion (Aspy et al., 2007; Eisenberg, Sieving, Bearinger, Swain, \& Resnick, 2006).

Sexual-minority women were less likely to report discussing issues related to sexual behavior or sexual health with both parents and friends than heterosexual participants. Though both groups of participants discussed similar sexual issues when they did discuss sexual behavior or sexual health, the small number of sexual-minority participants who reported support for these topics is notable. In particular, it is important that sexual-minority participants are not seeking advice on sexual performance and behavioral choices for their samesex experiences at the same rate that their heterosexual counterparts are talking to friends about these issues. It appears that these sexual issues are less salient for sexual-minority youth than for heterosexual youth at this stage of development. Additionally, sexual-minority youth may have fewer sources of support that they feel they can approach for help on these issues than do heterosexual youth.

Sexual-minority and heterosexual women also demonstrated similarities and differences in their accounts of support regarding dating and romantic relationships. Although both groups of women reported problems starting or ending dating relationship as well as problems within dating relationships, sexual-minority women described several unique difficulties in their dating and romantic relationships. They reported talking about distinct difficulties in their dating experiences, such as the effort involved in finding other sexual-minority women or becoming involved in the queer community on campus. Sexual-minority women also discussed having a crush on or being in a sexual relationship with women who identified as heterosexual. This left them in the precarious state of having feelings for someone who might decide to end their friendship or relationship at any point and presented a unique challenge for this population, a concern which has been documented elsewhere (Diamond, 2002; Morgan \& Thompson, 2006).

Identity negotiation and discrimination and violence appeared to be more salient sexual issues for sexualminority women than for heterosexual women. Emerging adulthood is an important period for sexual-minority women to develop their sexual orientation identities. As a result, we may have seen 
identity negotiation as an "issue" for sexual minority individuals in our study because they are likely in the early stages of their identity development, during which they are exploring their same-sex attractions and positions within the queer community (McCarn \& Fassinger, 1996). While many sexual-minority participants described coming out to a parent or friends as a form of social support, several unanticipated identity-related issues also emerged. Discussions concerning the expression of identity through hair length and clothing choices suggested that the queer community in college may place an emphasis on a certain "look" (Clarke \& Turner, 2007). Relationships with transgendered individuals also led two queer women to discuss identity issues with friends. Transgender issues as whole are understudied in psychological research (Grossman \& D'Augelli, 2006), and our results offer anecdotal evidence that relationships with transgender individuals may be an important site for identity (re)negotiations.

Interestingly, heterosexual women also reported discussing sexual identity negotiations with friends and parents. Though heterosexual women discussed this issue less frequently than sexual-minority women, it is important to recognize that although these women currently identify as heterosexual, they too are in the midst of sexual identity development and may also be engaging in explorations of samesex attractions. Identity negotiations may be more frequent in a particular subtype of heterosexual women, as research has shown various subtypes of straight identity in young women. For example, women who identify as mostly straight may be more likely to engage in identity negotiation than are women who identity as exclusively straight (see Thompson \& Morgan, 2008).

Discrimination and violence was another issue more commonly discussed by sexual-minority than heterosexual women. This is not surprising, given the frequency with which lesbian, bisexual, and queer women experience heterosexist prejudice (D'Augelli, 2003; Herek et al., 1997). Interestingly, many of the problems with discrimination they reported came from parents, friends, and acquaintances. This may be because rejection from family and friends is especially detrimental to sexual-minority youth's well-being (Hershberger, Pilkington, \& D'Augelli, 1997) and thus sexual-minority youth may find that these episodes are more salient and require greater support than discrimination from strangers. Additionally, previous research has found that experiences with discrimination are related to social identity development (Deaux and Ethier; 1998; Gurin \& Townsend, 1986). Results from this study suggest that sexual-minority youth do seek support from parents and friends for experiences with discrimination, which may serve as a means through which sexual-minority youth can transform discriminatory experiences into a catalyst for identity reexamination.

\section{Conclusions and Future Directions}

Different sexual issues emerged as important topics for the young women in this study. Sexual-minority women were less likely than heterosexual women to report discussing romantic relationships, sexual behavior, and sexual health. In contrast, sexualminority women were more likely than heterosexual women to discuss identity negotiations and discrimination and violence. Several possible explanations could account for this difference. First, romantic relationships, sexual behavior, and sexual health issues may have been overshadowed by issues of identity and discrimination for sexual-minority women, particularly at early "coming out" stages. The discrepancies in salience of these types of issues may be due to differential developmental trajectories of sexual minority and heterosexual youth, including earlier opportunities for heterosexual youth to engage in romantic relationships and to discuss sexual topics with friends and parents (Diamond, 2003). Second, sexual-minority women may be less likely to experience problems in their romantic relationships, sexual behavior, or sexual health. Third, sexualminority women may have had fewer sources on which they could rely for support on romantic relationships, sexual behavior, and sexual health than did heterosexual women. If this is the case, sexualminority women may not receive they support they need on these important topics. Future quantitative research could examine these explanations in more depth.

Previous research on sexual communication with parents and friends has not assessed discussions of sexual orientation identity or discrimination (DiIorio et al., 2003, Wood et al., 2002). This is likely because the majority of women who reported talking about these topics were sexual minorities and previous research-which has overlooked the role of sexual orientation-has not identified them as important issues. Our results suggest that these are highly salient topics for sexual-minority women in college. The availability of support for identity negotiations and experiences with discrimination may have important implications for well-being (Swann \& 
Spivey, 2004). Moreover, sexual-minority women were not the only ones discussing these topics. Thus, research exclusively focusing on heterosexual youth should also pay attention to these issues.

Results from this study also suggest that sexualminority women generally perceived support from parents and friends as less helpful than the heterosexual women in this study. Sexual-minority participants often implied that heterosexual parents and friends did not understand their unique experiences, and therefore were unable to give helpful advice. In other cases, sexual-minority women approached parents and friends who made clear in their response that they were not accepting of participants' sexual orientation. These occurrences often resulted in participants feeling disappointed, rejected, and angry. These results suggest that sexualminority women may experience additional difficulties in their sexual development due to friends and parents inability to provide helpful social support for sexual issues. Future research is needed to understand how parents and friends can be perceived as more helpful for sexual-minority individuals' sexual development. It is also important to keep in mind that, overall, support was perceived as helpful.

This research suggests several avenues for future research. First, our sample of college students was not able to establish how women's conversations with parents and friends change across development, which was anticipated despite the lack of age-related patterns found in this study. Similar research on sexual-minority and heterosexual women in high school would shed light on this issue. Additionally, because this sample is limited to college students, it is important that future research includes non-college young adult populations, as numerous impediments to seeking higher education exist for both sexual minority and heterosexual youth that may impact both the sexual issues youth experience and their relationships with parents and friends. Another limitations related to our sample is that few of the participants lived close to their parents; which may partially explain the low rate of support women reported from parents. Second, research examining sexual-minority and heterosexual men's reports of social support regarding sexual issues would ascertain similarities and differences between genders. Third, analyses that examined bisexual and lesbian women separately may be able to give further insight into the role of sexual orientation. Finally, the current study used open-ended questions that allowed us to describe two forms of sexual communication that previous research had overlooked. While this method allowed for the emergence of important information, it also resulted in narrow coding categories, categories with frequent "unable to code" responses, and the need for numerous comparative analyses. Future survey research that included questions about ongoing discussions regarding sexual identity negotiation and discrimination could allow more precise measurement of these conversations and topics, as well as insights into the relative frequency of discussions on a variety of topics.

In sum, this study is distinctive in that it examined communication with friends and parents about sexual issues as a form of social support. Results suggested that relationships with mothers and friends-especially sexual-minority friends-are important contexts for sexual development for young sexual-minority women. Identity negotiation may be an especially salient issue for sexual-minority women during this developmental period. Furthermore, the specific attention to sexual-minority women's experiences provided a novel and much needed analysis of how these women's sexual issues are both similar to and different from heterosexual women's sexual issues. As social support is related to several well-being outcomes (Friedlander et al., 2007; Jordan \& Deluty, 1998), parents, LGBTQ campus centers, counselors and others should be aware of the unique sexual issues sexual-minority youth experience. Further recognition of the similarities between sexualminority and heterosexual women's sexual issues and discussions about these issues, as well as sensitivity to the differences between these two populations, is needed.

\section{References}

Arnett, J. J. (2004). Emerging Adulthood: The winding road from the late teens through the twenties. New York: Oxford University Press.

Aspy, C. B., Vesely, S. K., Oman, R. F., Rodine, S., Marshall, L., \& McLeroy, K. (2006). Parental communication and youth sexual behaviour. Journal of Adolescence, 20, 449-466.

Ayres, M. M., Friedman, C. K., \& Leaper, C. (2007). Women's experiences of and responses to sexism in their everyday lives. Manuscript submitted for publication.

Beals, K. P., \& Peplau, L. A. (2005). Identity support, identity devaluation, and well-being among lesbians. Psychology of Women Quarterly, 29, 140-148.

Braun, V., \& Clarke, V. (2006). Using thematic analysis in psychology. Qualitative Research in Psychology, 3, 77-101. 
This is an author-produced, peer-reviewed version of this article. The final, definitive version of this document can be found online at Journal of Youth \& Adolescence (doi: 10.1007/s10964-008-9361-0) published by Springer. Copyright restrictions may apply.

Brown, B. B. (1999). "You're going out with who?": Peer group influences on adolescent romantic relationships. In W. Furman et al. (Eds.), The development of romantic relationships in adolescence (pp. 291-329). Cambridge, UK: Cambridge University Press.

Cain, R. (1991). Stigma management and gay identity development. Social Work, 36, 67-73.

Connolly, J. A., \& Goldberg, A. (1999). Romantic relationships in adolescence: The role of friends and peers in their emergence and development. In W. Furman et al. (Eds.), The development of romantic relationships in adolescence (pp. 266290). Cambridge, UK: Cambridge University Press.

D'Augelli, A. R. (2003). Lesbian and bisexual female youths aged 14 to 21: Developmental challenges and victimization experiences. Journal of Lesbian Studies, 7(4), 9-29.

D’Augelli, A. R., Grossman, A. H., \& Starks, M. T. (2005). Parents' awareness of lesbian, gay, and bisexual youths' sexual orientation. Journal of Marriage and Family, 67, 474-482.

Deaux, K., \& Ethier, K. A. (1998). Negotiating social identity. In J.K. Swim \& C.

Stangor (Eds.) Prejudice: The target's perceptive (pp. 301-323). San Diego, CA:

Academic Press.

Diamond, L. M. (2002). "Having a girlfriend without knowing it": Intimate friendships among adolescent sexual-minority women. Journal of Lesbian Studies, 6, 5-16.

Diamond, L.M. (2003). New paradigms for research on heterosexual and sexual-minority development. Journal of Clinical Child and Adolescent Psychology, 32, 490-498.

DiIorio, C., Kelley, M., \& Hockenberry-Eaton, M. (1999). Communication about sexual issues: Mothers, fathers, and friends. Journal of Adolescent Health, 24, 181-189.

DiIorio, C., Pluhar, E., \& Belcher, L. (2003). Parentchild communication about sexuality: A review of the literature from 1980-2002. Journal of HIV/AIDS Prevention \& Education for Adolescents \& Children, 5, 7-32.

Downie, J., \& Coates, R. (1999). The impact of gender on parent-child sexuality communication: Has anything changed? Sexual \& Marital Therapy, 14, 109-121.

Elizur, Y., \& Ziv, M. (2001). Family support and acceptance, gay male identity, and psychological adjustment: A path model. Family Processes, 40, 125-144.

Eisenberg, M. E., Sieving, R. E., Bearinger, L. H., Swain, C., \& Resnick, M. D. (2006). Parents' communication with adolescents about sexual behavior: A missed opportunity for prevention? Journal of Youth and Adolescence, 35, 893-902.

Evans, N. \& D'Augelli, A. R. (2001). Lesbians, gay men, and bisexual people in college. In R.C. SavinWilliams \& K.M. Cohen (Eds.), The lives of lesbians, gays, and bisexuals: Children to adults (pp. 201-226). Orlando, FL: Harcourt Brace College Publishers.

Foster, M. D. (2000). Positive and negative responses to personal discrimination: Does coping make a difference? The Journal of Social Psychology, 140, 93-106.

Friedlander, L. J., Reid, G. J., Shupak, N., \& Cribbie, R. (2007). Social support, self-esteem, and stress as predictors of adjustment to university among firstyear undergraduates. Journal of College Student Development, 48, 259-274.

Grossman, A. H., \& D'Augelli, A. R. (2006). Transgender youth: Invisible and vulnerable. Journal of Homosexuality, 51, 111-128.

Guilamo-Ramos, V., Dittus, P., Jaccard, J., Goldberg, V., Casillas, E., \& Bouris, A. (2006). The content and process of mother-adolescent communication about sex in latino families. Social Work Research, 30, 169-181.

Gurin, P., \& Townsend, A. (1986). Properties of gender identity and their implications

for gender consciousness. British Journal of Social Psychology, 25, 139-148.

Halpern-Felsher, B. L., Kropp, R. Y., Boyer, C. B., Tschann, J. M., \& Ellen, J. M. (2004). Adolescents' self-efficacy to communicate about sex: Its role in condom attitudes, commitment, and use. Adolescence, 39, 443-456.

Henderson, A. F. (1984). Homosexuality in the college years: Developmental differences between men and women. Journal of American College Health, 32, 216-219.

Herek, G. M., Gillis, J. R., Cogan, J. C., \& Glunt, E. K. (1997). Hate crime victimization among lesbian, gay, and bisexual adults. Journal of Interpersonal Violence, 12, 195-215.

Hershberger, S. L., Pilkington, N. W., \& D'Augelli, A. R. (1997). Predictors of suicide attempts among gay, lesbian, and bisexual youth. Journal of Adolescent Research, 12, 477-497.

Jordan, K. M., \& Deluty, R. H. (1998). Coming out for lesbian women: Its relation to anxiety, positive affectivity, self-esteem, and social support. Journal of Homosexuality, 35, 41-63.

Kim, J. L., \& Ward, L. M. (2007). Silence speaks volumes: Parental sexual communication among Asian American emerging adults. Journal of Adolescent Research, 22, 3-31. 
This is an author-produced, peer-reviewed version of this article. The final, definitive version of this document can be found online at Journal of Youth \& Adolescence (doi: 10.1007/s10964-008-9361-0) published by Springer. Copyright restrictions may apply.

King, B. M., \& Lorusso, J. (1997). Discussions in the home about sex: Different recollections by parents and children. Journal of Sex \& Marital Therapy, $23,52-60$.

Lasser, J., \& Tharinger, D. (2003). Visibility management in school and beyond: A qualitative study of gay, lesbian, bisexual youth. Journal of Adolescence, 26, 233-244.

Lee, R. M., \& Robbins, S. B. (1998). The relationship between social connectedness and anxiety, selfesteem, and social identity. Journal of Counseling Psychology, 45, 338-345.

Leets, L. (2002). Experiencing hate speech: Perceptions and responses to anti-semitism and antigay speech. Journal of Social Issues, 58, 341361.

Lefkowitz, E. S. (2005). "Things have gotten better": Developmental changes among emerging adults after the transition to university. Journal of Adolescent Research, 20, 40-63.

Lefkowitz, E. S., Boone, T. L., \& Shearer, C. L. (2004). Communication with best friends about sex-related topics during emerging adulthood. Journal of Youth and Adolescence, 33, 339-351.

Lefkowitz, E. S., \& Espinosa-Hernandez, G. (2007). Sex-related communication with mothers and close friends during the transition to university. Journal of Sex Research, 44, 17-27.

Lefkowitz, E. S., \& Gillen, M. M. (2006). "Sex is just a normal part of life": Sexuality in emerging adulthood. In J. J. Arnett, J. L. Tanner (Eds.), Emerging Adults in America: Coming of age in the $21^{\text {st }}$ Century (pp. 235-256). Washington DC: American Psychological Association.

Luhtanen, R. K. (2003). Identity, stigma management, and well-being: A Comparison of lesbians/bisexual women and gay/bisexual men. Journal of Lesbian Studies, 7, 85-100.

Luhtanen, R., \& Crocker, J. (1992). A collective selfesteem scale: Self-evaluation of one's social identity. Personality and Social Psychology Bulletin, 18, 302-318.

McCarn, S. R., \& Fassinger, R. E. (1996). Revisioning sexual minority identity formation: A new model of lesbian identity and its implications for counseling and research. The Counseling Psychologist, 24, 508-534.

Mohr, J. J., \& Fassinger, R. E. (2003). Selfacceptance and self-disclosure of sexual orientation in lesbian, gay, and bisexual adults: An attachment perspective. Journal of Counseling Psychology, 50, 282-295.

Moore, S., \& Rosenthal, D. (1991). Adolescents' perceptions of friends' and parents' attitudes toward sex and sexual risk-taking. Journal of
Community and Applied Social Psychology, 1, 189200.

Morgan, E. M., \& Thompson, E. M. (2006). Young women's sexual experiences within same-sex friendships: Discovering and defining bisexual and bi-curious identity. Journal of Bisexuality, 6 (3), 7 34.

Nesmith, A. A., Burton, D. L., \& Cosgrove, T. J. (1999). Gay, lesbian and bisexual youth and young adults: Social support in their own words. Journal of Homosexuality, 37, 95-108.

O’Sullivan, L. F., Meyer-Bahlburg, H. F. L., \& Watkins, B. X. (2001). Mother-daughter communication about sex among urban AfricanAmerican and Latino families. Journal of Adolescent Research, 16, 269-292.

Saltzburg, S. (2004). Learning that an adolescent child is gay or lesbian: The parent experience. Social Work, 49, 109-118.

Savin-Williams, R. C. (2005). The new gay teenager. Cambridge, MA: Harvard University Press.

Savin-Williams, R. C., \& Ream, G. L. (2003). Sex variations in the disclosure to parents of same-sex attractions. Journal of Family Psychology, 17, 429438.

Schouten, B. C., van den Putte, B., Pasmans, M., \& Meeuwesen, L. (2007). Parent-adolescent communication about sexuality: The role of adolescents' beliefs, subjective norm and perceived behavioral control. Patient Education and Counseling, 66, 75-83.

Sprecher, S., \& Felmlee, D. (1992). The influence of parents and friends on the quality and stability of romantic relationships: A three-wave longitudinal investigations. Journal of Marriage and the Family, 54, 888-900.

Swann, S. K., \& Spivey, C. A. (2004). The relationship between self-esteem and lesbian identity during adolescence. Child \& Adolescent Social Work Journal, 21, 629-646.

Thompson, E. M., \& Morgan, E. M. (2008). "Mostly straight" young women: Variations in sexual behavior and identity development. Developmental Psychology, 44, 15-21.

Treboux, D., \& Busch-Rossnagel, N. A. (1990). Social network influences on adolescent sexual attitudes and behaviors. Journal of Adolescent Research, 5, 175-189.

Ueno, K. (2005). Sexual orientation and psychological distress in adolescence: Examining interpersonal stressors and social support processes. Social Psychology Quarterly, 68, 258277.

Vincke, J., \& Van Heeringen, K. (2002). Confidant support and the mental wellbeing of lesbian and 
gay young adults: A longitudinal analysis. Journal of Community and Applied Social Psychology, 12, 181-193.

Weston, K. (1991). Families we choose: Lesbians, gay, and kinship. New York: Columbia University Press.

Wood, E., Senn, C. Y., Desmarais, S., Park L., \& Verberg, N. (2002). Sources of information about dating and their perceived influence on adolescents. Journal of Adolescent Research, 17, 401-417.

Wyss, S. E. (2004). 'This was my hell': The violence experienced by gender non-conforming youth in US high schools. International Journal of Qualitative Studies in Education, 17, 709-730. 
Table 1

Coding Categories for Types of Sexual Issues Discussed with Friends and Parents

\begin{tabular}{|c|c|c|}
\hline Sexual Issue & Description & Narrative Example \\
\hline $\begin{array}{l}\text { Dating and } \\
\text { relationships }\end{array}$ & $\begin{array}{l}\text { Wanting to date, problems } \\
\text { in a relationship, breaking } \\
\text { up, hooking up }\end{array}$ & $\begin{array}{l}\text { The girl I fell for a year ago had been } \\
\text { messing with me a lot; getting with me... } \\
\text { then giving me all of these excuses why not } \\
\text { to be with me and breaking up with me. }\end{array}$ \\
\hline Sexual behavior & $\begin{array}{l}\text { Practical tips of sexual } \\
\text { activities, own or partner's } \\
\text { sex drive, sexual desire }\end{array}$ & $\begin{array}{l}\text { I discussed a problem with a sexual } \\
\text { position--I didn't really know quite how to } \\
\text { do it. }\end{array}$ \\
\hline Sexual health & $\begin{array}{l}\text { Virginity, menstrual } \\
\text { periods, birth control, } \\
\text { pregnancy, STIs, painful } \\
\text { sex, inability to orgasm }\end{array}$ & $\begin{array}{l}\text { I had lost my virginity to a boy that I was } \\
\text { friends with. However, we did not use a } \\
\text { condom when having sex and I was worried } \\
\text { about contracting a STI. }\end{array}$ \\
\hline $\begin{array}{l}\text { Identity } \\
\text { negotiation }\end{array}$ & $\begin{array}{l}\text { Questioning and } \\
\text { (re)defining one's sexual } \\
\text { orientation, coming out to } \\
\text { others }\end{array}$ & $\begin{array}{l}\text { A close guy friend likes me and asked me } \\
\text { out and i didn't know whether or not to date } \\
\text { him because I'm still figuring out my } \\
\text { sexuality. }\end{array}$ \\
\hline Discrimination & $\begin{array}{l}\text { Experiences with sexist or } \\
\text { heterosexist bias }\end{array}$ & $\begin{array}{l}\text { I was having a difficult time with my sister } \\
\text { and my high school friends making } \\
\text { inappropriate homophobic jokes around } \\
\text { me. }\end{array}$ \\
\hline
\end{tabular}

Table 2

Comparisons between Sexual-Minority (SM) and Heterosexual (H) Participants' Sexual Issues

Discussed with Friends and Parents

\begin{tabular}{lcccccc}
\hline & \multicolumn{3}{c}{ Parents } & \multicolumn{3}{c}{ Friends } \\
\cline { 2 - 7 } Sexual Issue & $\mathrm{SM}$ & $\mathrm{H}$ & $\chi^{2}$ & $\mathrm{SM}$ & $\mathrm{H}$ & $\chi^{2}$ \\
\hline Dating and relationships & $14 \%$ & $25 \%$ & $3.57 \dagger$ & $37 \%$ & $52 \%$ & $4.77^{*}$ \\
Sexual behavior & $1 \%$ & $7 \%$ & $3.88 *$ & $7 \%$ & $24 \%$ & $9.03 * *$ \\
Sexual health & $5 \%$ & $20 \%$ & $8.79 * *$ & $0 \%$ & $8 \%$ & $6.93 * *$ \\
Identity negotiation & $20 \%$ & $4 \%$ & $13.06^{* * *}$ & $39 \%$ & $7 \%$ & $29.88^{* * *}$ \\
Discrimination and violence & $7 \%$ & $3 \%$ & 1.81 & $14 \%$ & $3 \%$ & $7.67 * *$ \\
\hline
\end{tabular}

Note. Chi-square statistics assess differences between the sexual-minority $(N=88)$ and heterosexual participants $(N=141)$.

$\dagger p<.10, * p<.05, * * p<.01, * * * p<.001$ 